\title{
From Smart Buildings and Cities to Smart Living
}

\author{
Felipe Samarán Salóa,1 \\ ${ }^{\text {a } U n i v e r s i d a d ~ F r a n c i s c o ~ d e ~ V i t o r i a, ~ M a d r i d, ~ S p a i n ~}$
}

\begin{abstract}
We are drowning in information while starving for wisdom said the twotime winner of the Pulitzer Prize Edward Osborne Wilson. We are attached 24 hours to our "smart" phone that gets us closer to those who are far away and keeps us apart from those who are near, and we want to live in "smart" buildings and "smart" cities where systems are used and data can be gathered to save energy, create comfortable ambiances, regulate traffic, or deal with our waste products, but we surely need to reconsider what "Smart" living is all about. From the roman empire to the actual high-rise buildings, through the modern movement leaded by Le Corbusier, each time has used the technology available, but neither of the great master pieces of architecture and urbanism is remembered by the technology that made it possible but by Its ability to seduce the minds, hearts and souls of its habitants and the generations that came after them. It is essential to know that we truly need, to clarify WHY and WHAT FOR we do things before we solve or engage ourselves in HOW we make it happen.
\end{abstract}

Keywords. Information, wisdom, smart living, architecture, urbanism

\footnotetext{
${ }^{1}$ Corresponding Author: Universidad Francisco de Vitoria, Madrid, Spain; E-mail: f.samaran@ufv.es
} 